holds both for rapidly succeeding stimuli and for single stimulations.

The inertia of the retina against chemical disintegration may be accepted as a fact. The amount of this disintegration determines the intensity of the sensation. A strong stimulus acting for half the time necessary to produce its maximum effect gives rise to a sensation of exactly the same intensity as that produced by half as strong a stimulus producing its maximum effect. The stronger sensation does contain the weaker, temporally, for between the first moment of stimulation and the moment of maximum effect the disintegrating process will pass through the series $o$ to this maximum. Each step in this series is the basis of a sensation of corresponding intensity. While these growing sensations as such do not enter consciousness, they may be the elements of our feeling of 'more' or 'less,' as concerning the intensity of sensations.

In this way we may conceive of a physiological basis of intensity which does not give a qualitative difference to the sensation.

\title{
II. Normal Motor Automatism.
}

\section{BY LEON M. SOLOMONS AND GERTRUDE STEIN.}

It is well known that many hysterical subjects exhibit a remarkable development of the subconscious life, amounting, in many cases, to that most interesting phenomenon known as double personality. It has often been argued that the performances of these 'second personalities' are essentially different from the merely automatic movements of ordinary people-so different, in fact, as to compel us to accept the name 'second personality' as a literal expression of the real state of things. Against this view it is urged that we underestimate the automatic powers of the normal subject. We are told that many of the acts which we usually do quite consciously might really be done without consciousness. In support of this assertion such facts are pointed out, as men completely undressing without knowing it, when their attention is distracted by other matters. If this 
latter explanation is to hold, however, something more than assertion must be forthcoming. The limit of automatism is something that is essentially capable of demonstration by experimental methods, and its investigation forms the subject of this paper.

It must not be understood that any attempt is made to answer the vexed question of a so-called 'subliminal consciousness.' This question cannot be settled experimentally, unless it be admitted beforehand that the automatic acts of normal subjects, between which and the 'second personality' an analogy is asserted, are themselves unaccompanied by consciousness. But this is by no means universally admitted. The question of consciousness, in all cases where it is not directly experienced, is essentially a philosophical one, and the facts of psychology have little, comparatively, to do with it. But the question of whether the performances of the 'second personality' are to be allied to the automatic acts of ordinary people, or whether they are to be allied to those acts which never go on save in the full glare of consciousness-by the aid of reflection, judgment and will; this question is perfectly definite, capable of satisfactory solution by observation and experiment, and of great importance to scientific psychology.

The object of our experiments, then, was primarily to determine the limits of normal automatism, and, if possible, show them to be really equal to the explanation of the second personality; and incidentally to study as carefully as possible the process by which a reaction becomes automatic. Above all, we wished to avoid anything like a real production of a second personality. For the experiments to really settle the point at issue it was essential that no suspicion should rest upon the complete ' normality' of the subject throughout the experiments. Our idea was to reproduce rather the essential elements of the ' second personality,' if possible, in so far as they consist of definite motor reactions unaccompanied by consciousness-or shall we say, out of deference to the subliminal consciousness theory, unaccompanied by 'conscious consciousness.' These elements appeared to us to be conveniently considered under four groups, as follows : 
I. General tendency to movement without conscious motor impulse.

2. Tendency of an idea in the mind to go over into a movement involuntarily and unconsciously.

3. Tendency of a sensory current to pass over into a motor reaction subconsciously.

4. Unconscious exercise of memory and invention.

In the complete second personality all these elements exist at once. We proposed to prove their existence in normal subjects separately.

I. General tendency to movement. For these experiments a planchette was used. Both of us had previously tried in vain to ' write planchette.' Neither of us has any aptitude for will ing games, etc. We may both as far as we know stand as representatives of the perfectly normal-or perfectly ordinarybeing, so far as hysteria is concerned.

The planchette used was a glass plate mounted on metal balls, with a metal arm holding a pencil. The subject placed one hand firmly on this and then proceeded to get himself as deeply interested in a novel as possible. In this way it is easy to show that although the arm does not really move spontaneously, yet any movement once started up tends to continue of itself. Further, very slight stimuli are capable of starting the movement. For example, as soon as the position of the arm grows uncomfortable, or would be uncomfortable if the subject attended to it, it is likely to begin movement. By slightly moving the planchette it is easy to start the arm to moving, after which it will continue of itself if not deliberately checked by the will of the subject. If the story that the subject is reading be sufficiently interesting, all this goes on without his knowledge. Where he is conscious of the movements of his arm, however, they appear to him to be extra personal. It is not he but his arm that is doing it. He cannot say whether his arm is moving spontaneously or whether it is being moved by the operator. Later, if allowed practice, he may learn to make this distinction, but the movements do not at all lose their extra personal character. He readily perceives that they are of two kinds de pending on whether the operator moves the planchette or his 
arm moves, but both these movements seem equally disconnected with himself. He gains his knowledge of the movement purely through sensations from the arm. He has no feeling of intention or desire; no fore-knowledge of what the movement is to be. As we shall see, this feeling of extra personality appears in all our experiments whenever knowledge of movement is gained purely from sensations-whenever there is no preceding feeling of intention. Where the attention of the subject is completely distracted by the reading, all knowledge of the experiment disappears and the movements go on entirely without his knowledge and quite as well. The only interference comes if the story gets too exciting, when emotional reflexes are likely to interfere either by causing violent movement or by stopping all movement.

Sometimes it is possible to 'teach' the arm some special movement, which it will then go on making of its own accord. For example, the operator may start the planchette to making $m$ strokes, and as soon as the hand has caught the movementshown by the absence of resistance-stop. The arm goes on making the strokes. Gradually, however, it gets them more and more out of shape until it has got into an elliptical movement which is more natural to it, apparently. When this habit -that of making wide elliptical movements, has become well developed, the arm loses its 'suggestiblity' and can no longer be taught special movements. The moment the planchette is released it starts back to its own movement. In connection with this natural movement it should be noticed that it is much more difficult for the subject to distinguish between spontaneous movements and movements impressed by the operator, when the impressed movement is the natural one, than when it is widely different from this. Apparently the arm quickly falls in to the suggested movement when it is its own natural movement; while in other cases this falling in is delayed, resulting in a tension in the muscles of the arm representing its ' hanging back' behind the movement impressed on the hand by the motion of the planchette. It is by learning to recognize this tension that the subject is enabled to distinguish between spontaneous and impressed movements. Introspectively this seemed 
to be about the method, that is, and it agrees well with the fact just noted.

From these experiments we concluded that in normal subjects there is a general tendency to movement from purely sensory stimuli, independent of any conscious motor impulse or volition. This tendency is ordinarily inhibited by the will, but comes out as soon as the attention of the subject is removed. This tendency to stop automatic movements and bring them under the control of the will is very strong. Nothing is more difficult than to allow a movement of which we are conscious to go on of itself. The desire to take charge of it is almost irresistible. But as we shall see later it is a habit that can be overcome, and a trained subject can watch his automatic movements without interfering with their complete non-voluntariness.

From now on, having demonstrated the tendency to spontaneous movement, we did not hesitate to make the mere movement element voluntary.

2. Tendency of ideas to go over into movement. For these experiments the subject was given a pencil which he kept moving over a paper as though writing-a sort of continuous movement-he meanwhile being engaged in reading a story. The writing movements quickly become automatic, and nothing prevents the subject from giving his full attention to his reading. Under these circumstances there is a very decided tendency to write down words read, especially simple words such as the, in, it, etc.

Sometimes the writing of the word was completely unconscious, but more often the subject knew what was going on. His knowledge, however, was obtained by sensations from the arm. He was conscious that he just had written a word, not that he was about to do so. While mere scribbling went on the subject would scarcely be conscious that he was doing anything; but the writing of a word-either because of the different character of the movements, or their greater energy-seemed to attract his attention. Small words would usually be completely written before the subject knew about it, but large words would only get started. But even where there was no interference from the attraction of the voluntary attention large words were 
seldom attempted, and, still more rarely, more than just begun. This fact may, however, very easily be referred to the fact that reading is so much faster than writing that subsequent words, with different motor reactions, interfere with the writing of a long word. But a word that can be written with one impulse is not affected by this. Succeeding words may be read before it is written, but their motor impulses do not reach the arm in time to interfere.

As experiments of this kind were of necessity also carried on during the next series, they were not prolonged.

3. Unconscious passage of sensation into motor reaction.

The first form of this which we tried was writing at dictation. As in the other experiments, the subject's attention was occupied as fully as possible in reading. He kept his pencil moving constantly, scribbling when no dictation was going on. These experiments were by far the most difficult we attempted, and required the most training.

At the first attempt the subject is entirely unable to follow what he is reading. He reads, but does not get the meaning. $\mathrm{He}$ is painfully conscious of the experiment and everything connected with it. He has an irresistible tendency to stop whenever a word is given to him and attend to that until it is written, and then go on with his reading. In a word, the conditions demanded by the experiment are opposed to all his habits of attention, and the successful carrying out of the experiment demanded that these habits be overcome. And yet, in spite of this, there were momentary lapses of consciousness right from the start. Very uncertain in character and very rare, but enough to encourage us to persevere.

One very quickly gets sufficiently accustomed to the experiment to follow the story. But the habit of turning the attention to the writing whenever a word is given is difficult to overcome. The facility one acquires in rapidly shifting the attention from reading to writing and back, without confusion or effort, is really quite remarkable. Where at first the effort produces nothing but confusion of the worst kind, in a few hours' practice one is able to read his story with perfect ease and comfort, undisturbed by the constant interruptions for writing, even when 
these are quite frequent-say every I $_{5}$ or 20 seconds. But when the story grows interesting the attention is held too powerfully for this, and cases of pure automatism begin to appear frequently. The word is written or half written before the subject knows anything about it, or perhaps he never knows about it. For overcoming this habit of attention we found constant repetition of one word of great value. By such methods as these we gradually began to get control of our attention, and produce the necessary conditions for the experiment. There are four elements to be distinguished in the writing of a word at dictation. I, The heard sound; 2 , the formation of a motor impulse ; 3 , a feeling of effort ; 4, sensation from the arm telling of the written word. 2 and 3 are frequently indistinguishable in consciousness, but they are distinct, for they come and go under different circumstances. 2 consists of a melange of visual and kinæsthetic material-whatever ordinarily innervates our writing - as well as other elements not easily described, and perhaps really a direct consciousness of a motor current. On this point more later.

The first thing to disappear is the feeling of effort. We hear the word, have an idea of how it should be written, and then it is written. The writing seems perfectly voluntary, but there is no sense of difficulty, of 'something accomplished.' The strong self-consciousness that accompanies a concentration of the will at any point is entirely lacking, but nevertheless the writing feels thoroughly voluntary. This feeling of effort reappears after a while, and then it is time to stop the experiment, for the arm is tired. It comes back also if the voice of the operator falls too low.

The next step is the disappearance of the motor impulse. The writing becomes non-voluntary. We hear the word, and we know what we have written; that is all. This is the general condition of things throughout the experiment, after the preliminary training is over. The writing is conscious, but non-voluntary and largely extra personal. The feeling that the writing is our writing seems to disappear with the motor impulse. This fact is doubly significant here, for in this case we have a fore knowledge of what the written word will be, 
since we hear this dictated word. The reaction of the arm is not really unexpected, yet it is still not felt to belong to the willing subject. It sometimes seemed that the visual element of the motor impulse might remain, and the reaction still feel extra personal. But opportunities for observing this were few, and we advance the proposition with hesitation. If true it would lead to the conclusion that the motor impulse contains a direct consciousness of a motor current, which is the essential element in an act of will ; for the kinæsthetic element of the impulse is, with us, extremely slight, if, indeed, it exists at all in ordinary unstudied movements. This view, that the motor impulses, descending from the higher centers to the lower, are accompanied by consciousness, is one that all our experiments have tended to impress powerfully upon us. Yet the tangible, 'statable' evidence for it is extremely slight. It seems to be an unconsciously produced conviction proceeding from a multitude of elusive trifles.

Real automatism, that is, dropping out of consciousness of the other two elements, heard sound, and return sensations from the arm, comes only at intervals and for short periods at a time. But it comes zohenever the attention is sufficiently distracted. In no case does withdrawal of the attention interfere in the least with the reaction. The writing goes on just the same, but below consciousness. The only exception to this comes on the emotional side. If the story gets very exciting the muscular tension, which is one of the expressions of intense suspense, stops the arm movements entirely, and, of course, with that the possibility of writing words. Also, in very exciting parts, the tendency to write words from one's reading is also increased, but this does not interfere much.

A very distinct stage in the process of becoming unconscious is where we find the word started before we are conscious of having heard it, or we learn the word first from our writing, and then perhaps recall its sound by the memory afterimage; or we are uncertain what word was dictated, and while we are wondering the word is written. Every once in a while the story grows interesting, and we return to ourselves with a start to find that we have been going on writing just the 
same. In this connection it is important to notice that the return to consciousness is always from the motor side. We suddenly become aware that our hand is writing something. It is never the sound that recalls us. This, of course, may be an individual peculiarity to a certain extent, and possibly would not be true of everyone. Yet, Miss Stein has a strong auditory consciousness, and sounds usually determine the direction of her attention.

For a long time during these experiments nothing was more marked than the complete failure of automatism as soon as the voice fell below a certain degree of loudness. The moment that happened the writing would not continue without the formation of a motor impulse, usually accompanied by a feeling of effort. This minimal loudness was so near the point of difficult hearing that we could not say whether the feeling of effort really belonged to the identification of the sound, or the formation of the motor impulse.

After long practice this phenomenon disappeared quite suddenly. The minimum loudness took a big drop to a point rather below easy hearing. It now became very much easier not to attend to the dictation, and the intervals of complete unconsciousness lasted much longer, and occurred much more frequently. Our results were now entirely satisfactory and we stopped the experiment.

As to the extent of the unconscious intervals, they frequently extended for five or six words with complete unconsciousness, while the successive occurrence of several such intervals, separated only by momentary flashes of consciousness, was not uncommon.

As to the test for unconsciousness, of course, in the nature of things, the only test can be that of memory. One cannot directly observe unconsciousness. Here it will, of course, be said that there is no proof that it is not merely memory that is at fault. We may be momentarily conscious of these reactions, but forget them. Of course, the same objection can be made to any alleged case of automatism, and the fundamental object of these experiments, to establish an analogy between the acts of the second personality and what is ordinarily called automatism, 
is not affected by this objection. There is no proof, save that of memory, for the performance of the so-called 'split-off consciousness' being other than a performance of the primary consciousness, nor for any of the simple reflexes ordinarily called unconscious being really not cases of rapid alternation. Our problem, being purely one of similarity between two well marked systems of phenomena, is independent of the ultimate interpretation of either group. We simply wish to show that what holds for one holds also for the other.

Nevertheless, this question of alternation without memory, versus real unconsciousness, is an important one, and as we made observations bearing on this subject it will be well to record them here.

In brief, what we observed was a phenomenon different from true unconsciousness, but corresponding almost exactly to the conception of alternation without memory. The subject was absolutely unable to recall a single word written, but nevertheless felt quite certain that he had been writing, and that he had been conscious of every word as he wrote it. This, in fact, was the general condition of things through the greater part of the experiments, after training was well under way. The same sentence might be dictated to the subject over and over again, and at the end of the series he would not know what it was. Yet not a single instance of what we have called unconsciousness occurred during the interval. Of course, this is not conclusive, for obviously there is memory of some kind even in this case, though not a memory of what was written. But the important point is that real unconsciousness appeared, not as a last stage of this, but as an altogether different phenomenon coming quite suddenly, and under different conditions. The consciousness without memory seems to approach as its limit, simply a condition in which the subject has not the faintest inkling of what he has written, but feels quite sure that he has been writing. It shows no tendency to pass beyond this into real unconsciousness. It seems to depend on the lack of associations between the different words-one word going out of consciousness before another has come in to be associated with it. It is facilitated by slow dictation. And conversely real 
unconsciousness appears not as a final stage of a gradually decreasing memory, but quite suddenly. It may break into a period of consciousness without memory, and be followed by such again, but it is equally likely to break into a period of complete memory. In either case it comes entirely unheralded by any transition form, and departs as suddenly and silently. It does not seem to depend upon association elements at all-is entirely independent of the speed of dictation up to the limit of writing speed.

This identification of a phenomenon so strikingly in accord with the 'alternation-without-memory' theory, yet so strikingly different from the well known phenomenon of unconsciousness, seems to us to leave little room for reasonable doubt as to the correctness of the common sense view of the unconscious-the view, that is, that it really is unconscious.

This phenomenon of failure of memory, in spite of the presence of consciousness, will at once be recognized as corresponding quite closely to some well known hysterical phenomena. We shall come across more instructive instances of it later on in automatic reading.

It will perhaps be objected to these experiments that the long training required to bring them out destroys their value, for the hysterique does all these things without special training. It will be said that to prove that the second personality uses nothing but habitual brain paths it is scarcely permissible to establish new paths.

But it must be remembered that our training was purely a training of the attention. Our trouble never came from a faiture of reaction, but from a functioning of the attention. It was our inability to take our minds off of the experiment that interfered. From the start, whenever, by good luck, this did happen, the reaction went on automatically. (The exception noted from intense excitement is, of course, of no importance in this connection.) The hysterique has no trouble here, for he is unable to attend to the sensation, attention to which bothered us. It is his anæthesias which make automatism possible. What in his case is done for him by his disease we had to do by acquiring a control over our attention. 
But if there was no real creation of new paths, it will be objected that yet the lowering of the minimal loudness of dictation, so essential to the success of the experiment, was at least an opening up and 'smoothing' of old paths. This is doubtless true, but it must be remembered that training of this kind the hysterique can get during the early stages of his disease. The formation of a second personality is a late development, and sub-conscious acts of an irregular character occur for a long time before the organized second personality appears. During this stage paths which are not yet well worn may be opened up. It will be remembered that in our experiments we found automatism easier when the arm was fresh. When tired it suddenly failed. Apparently, the energy reaching it along the automatic path is no longer sufficient. Produce this backwards now. Imagine an arm in the condition of 'chronic rest' of an hysterical paralysis. Is it not altogether likely that it often acquires great sensitiveness from this, so that stimuli reaching it along the automatic path, not strong enough to produce a reaction in a normally exercised arm, may yet produce a reaction in the hyperæsthetic arm? In this way old paths may gradually be widened, until the second personality emerges -possibly with a sub-conscious hyperæsthesia to trouble some psychical researcher.

Automatic Reading.-This is a very pretty experiment because it is quite easy and the results are very satisfactory. The subject reads in a low voice, and preferably something comparatively uninteresting, while the operator reads to him an interesting story. If he does not go insane during the first few trials he will quickly learn to concentrate his attention fully on what is being read to him, yet go on reading just the same. The reading becomes completely unconscious for periods of as much as a page. In this experiment when well under way, it is the moments of conciousness that are rare. One remembers having read something at the beginning of the paragraph and suddenly finds himself at its end. All between is a blank. One feels that he surely must simply have suddenly let his eyes drop from one end to the other. Often, though the reading is entirely unconscious he is conscious of a confused murmer heard all the 
time-the sound of his voice-but it bears about the same relation to his consciousness as the murmer of the stream, beside which one reads on a summer day-a general background of sound, not belonging to anything in particular.

The reading is not entirely lacking in expression, and the pauses are made quite properly. But the tone is usually more monotonous than the reader's normal. Absurd mistakes are occasionly made in the reading of words-substitutions similar in sound but utterly different in sense. The usual suggestibility of the unconscious is shown in a tendency to insert words from the reading which is attended to. (Here it will be noticed appears an automatic path from ear to mouth.) The words read must be familiar for the automatism to work well. Dialect stories do not go well at all.

The eye movements in this experiment are most interesting. The tendency to raise ones eyes from the book one is reading, and turn them on the person one is listening to, is very strong. A compromise is frequently the result. One's eyes are focused at a point a little above the book, and the reading goes on out of the corner of one's eye. Tendencies of this kind, however, are not so hard to overcome as one supposes the first time he tries. Eye movements here seem to be simply a result of attention, not in any sense the thing itself.

The feeling of extra personality appeared here too. Whenever it happened, that is, that the subject after a period of automatic reading suddenly began to hear what he was reading, his voice seemed as though that of another person. This effect did not disappear immediately when he began to see the printed words. Not until he had, as it were, 'taken in hand' the process by which printed words pass into speech, did extra-personality disappear from his reading.

When both persons read with equal loudness, each trying to pay attention to the other, the conditions are very different. In the simpler experiments the problem is simply to pay attention to sounds, and not to sight and speech. When both read equally loud, however, this is not enough. It is easy enough to get the reading automatic, but to listen to another person's voice and not to one's own is another matter. Here comes in the distinc- 
tion pointed out in the automatic writing between the mere entering of consciousness and the establishment of associations giving memory and meaning. It is not possible to hear only the other person's voice. If the centers for the consciousness of sound are in a condition to respond to afferent currents at all they respond to all, or, at least, do not discriminate except at haphazard. But it is possible to graspthe meaning of one only, the other being in the condition of the words written, but not remembered, in the automatic writing. This affords a most interesting field of observation, but as it concerns a different problem from the one in hand I speak no further of it here. It will form part of another series of experiments having as their problem the general relation of attention and memory. These two elements of attention are very distinct. The one a mere attending to certain classes of sensations-a physiological distribution-the other inseparably bound up with the laws of association and the act of thinking things together, the holding before the mind of a general conception which is gradually modified by new information.

4. Unconscious memory and invention.-The first experiments in this line were on automatic speaking, and were carried out in connection with the automatic writing at dictation. For this purpose the person writing read aloud while the person dictating listened to the reading. In this way it not infrequently happened that, at interesting parts of the story, we would have the curious phenomenon of one person unconsciously dictating sentences which the other unconsciously wrote down; both persons meanwhile being absorbed in some thrilling story.

In this experiment, as in the automatic reading already described, whenever it happened that the speaker became aware of his dictation solely by hearing his own voice, his voice seemed strange and extra personal. The dictation was of the character that we already had used during the experiments, short, simple words strung along grammatically, but not representing usually any special thought.

Spontaneous automatic writing.-This became quite easy after a little practice. We had now gained so much control 
over our habits of attention that distraction by reading was almost unnecessary. Miss Stein found it sufficient distraction often to simply read what her arm wrote, but following three or four words behind her pencil. All the phenomena observed in the writing at dictation were confirmed here-the order of disappearance from consciousness, extra personality, difference between memory and consciousness, etc. Two very interesting phenomena were here observed for the first time.

$A$ marked tendency to repetition.-A phrase would seem to get into the head and keep repeating itself at every opportunity, and hang over from day to day even. The stuff written was grammatical, and the words and phrases fitted together all right, but there was not much connected thought. The unconsciousness was broken into every six or seven words by flashes of consciousness, so that one cannot be sure but what the slight element of connected thought which occasionally appeared was due to these flashes of consciousness. But the ability to write stuff that sounds all right, without consciousness, was fairly well demonstrated by the experiments. Here are a few specimens:

" Hence there is no possible way of avoiding what I have spoken of, and if this is not believed by the people of whom you have spoken, then it is not possible to prevent the people of whom you have spoken so glibly. . . ."

Here is a bit more poetical than intelligible:

"When he could not be the longest and thus to be, and thus to be, the strongest."

And here one that is neither:

"This long time when he did this best time, and he could thus have been bound, and in this long time, when he could be this to first use of this long time ....."

In this automatic writing from invention appeared more strongly than anywhere else the fact that the motor impulse is necessary for the feeling of personality. For it was easy here for long periods to get the process in a condition where there was often an expectation of what word would be written, but no intention to write it. One watched his arm with an idle curiosity, wondering whether or no the expected word would be written. In these experiments more than in any others did we 
feel the need of supposing that conciousness accompanies motor currents. If we wrote without watching what we wrote the writing was rapid and very illegible. By watching the writing, however, or, more correctly, by keeping our eyes on it, for there was no attention to it, the writing was kept even, legible, and at moderate speed. The control of movements by return sensation of sight is thus demonstrated to be an automatic process.

Subconscious exercise of memory. - The subject while his attention was distracted by listening to reading wrote some bit of poetry well known to him. The object was to see whether the memory, though in purely sound and speech terms, would yet go over into writing reactions automatically. The things written were bits of poetry that the subject had often repeated to himself, but never written. The experiment was successful. Its significance is that it shows that an act, to go on automatically, need not have been done before, provided all its elements have been done before. Thus in this case we have a combination of the automatic going over of ideas, or words, into writing reactions, the tendency of words written by the hand to call up in the mind their corresponding sound, and this to call up the next word of the poem which had been memorized in sound terms. The experiment is thus a justification of our general method of splitting up the second personality into its elements, and reproducing them automatically, instead of striving to reproduce the entire phenomenon at once.

Some general characteristics of the experiments.-In all automatism the tendency toward increased speed is marked. Writing tends towards a pace that very quickly tires, reading towards a rapidity that prevents distinct articulation, dictating toward a speed that soon becomes hopelessly fast for the writer. The increase of speed is gradual, and occasional corrections during flashes of consciousness suffice usually to keep down the tendency. The monotony of the automatic reading has its parallel in automatic writing. In the writing at dictation for example it was usually possible for the operator to tell from the way a word was written whether or not it had been entirely non-voluntary. The dropping out of consciousness produced no change in the writing if it was already in the non-voluntary 
stage. But the presence or absence of the motor impulse made an enormous difference. The purely non-voluntary writing has a perfect ease and smoothness about it, and a perfect characterlessness. The change is not in the appearance of the writing, but in the hand movements. The pencil movements are more regular in speed, and unaccented, while in the voluntary movements the writing is more jerky.

For distracting attention, literature that is easily followed and emotional in character is by far the best. The advantage of the emotional element is, of course, simply its well-known hold upon the attention. But the need that it shall be something which does not demand a reaction from the intellect of the person is a subtler affair. The mechanism appears to be this, that when the idea cannot be grasped without a conscious effort to keep past facts in mind to compare with present, the attention is kept in a general condition of alertness, unfavorable to the complete neglect of any class of sensations. These general attitudes of attention are very hard to describe, but very interesting and very distinct. One of the most suggestive, for example, was this: We noticed on several occasions that if, for any reason, we had missed any portion of the story, and wanted to go back and read it over again, the doing this stopped the automatic writing. This curious effect we traced to a general feeling of 'keeping things in check' for a moment. The idea of stopping the reading and going back brought the feeling that things must be held in check until this back reading had been done; and this feeling of holding in check expressed itself in stopping the automatic writing, as the intense excitement and suspense did, save that there was no marked muscular tension here.

Anything which favored rapid changes of attention was unfavorable to keeping the attention off the experiment. Stories that moved along smoothly and quickly and called for no reaction but an emotional one were the most favorable. Any stirring up of the attention was likely to bring it back to the experiment.

General Summary.-How far now have we gone toward proving our general proposition? We may sum up the experi- 
ments by saying that a large number of acts ordinarily called intelligent, such as reading, writing, etc., can go on quite automatically in ordinary people. We have shown a general tendency, on the part of normal people, to act, without any express desire or conscious volition, in a manner in general accord with the previous habits of the person, and showing a full possession of the faculty of memory; and that these acts may go on just as well outside the field of consciousness; that for them, not only volition is unnecessary, but that consciousness as well is entirely superfluous and plays a purely cognitive part, when present. By consciousness we here mean, of course, 'empirical consciousness' or 'conscious consciousness,' as we have called it elsewhere. A possible split off consciousness is expressly excluded from consideration for the reasons given in the introduction.

That the second personality shows, in general, no abilities beyond this will, I think, be readily admitted. But it will be claimed that in exceptional cases the performances of the second personality involve something more-a real judgment and discrimination, or the keeping before the mind of an idea which is gradually elaborated.

Of course, it is not possible to enter into a complete discussion of the theory of these phenomena here. But a few words in defense of the main contention of our experiments will not be out of place. We must leave out at once all the alleged phenomena of spiritualism, as being still under dispute and being equally inexplicable on either of the two theories between which it is the purpose of these experiments to decide. Ruling these out there remains a small number of cases apparently not fully explained as automatic, if our experiments be taken as showing the limit of automatism. These cases may be divided into two groups. The first are those where the reactions seem to be rather too intelligent to involve nothing more than habit and memory. These need not offer much difficulty. Without a full knowledge of the past history of the patient, it is not possible to tell just where the limits of habit lie. There is opportunity for large individual difference here, and we must allow for it. What one person would have to think about, another 
may be so familiar with as to do quite without thought. It will usually be far more reasonable to suppose special habits for unusual cases than to fly in the face of all analogy and suppose a real second personality present. It must be remembered, too, that real unconsciousness is hard to prove.

Our observations on consciousness without memory show that in many cases the 'second personality' may be helped over a knotty point by flashes of primary personality, and exceptional cases would have to be examined from this standpoint before used to overthrow the automaton theory.

The other group embraces the cases that appear in connection with hystero-epilepsy and post-hypnotic suggestion. The peculiarity of these cases is that instead of one act forming the stimulus for the succeeding one-which would involve nothing but simple association-we have a dominant idea present which guides proceedings. This, of course, suggests the action of voluntary attention. It is like the man who is at work on a problem and voluntarily keeps the problem before his mind until the right associations have been called up by it. The diffculty presented by these cases disappears, however, as soon as we remember that here we have to do with an essentially new element-a fixed idea-either the subconscious fixed idea of hystero-epilepsy, or the apparently similar subconscious idea of post-hypnotic suggestion. The presence of these fully explains this apparently voluntary and actively attentive character of the acts without calling in any aid from the voluntary attention. The mechanism of these fixed ideas need not concern us. If it be held that they are kept before the mind by a split of will, this is a theory of fixed ideas, which would have to be considered on its own merits. Our problem is not involved in it essentially.

If, then, it be admitted that these experiments satisfactorily answer the question raised at the outset, if they really show a complete analogy between the performances of the second personality and the automatic acts of normal persons, what general view of hysteria do they suggest?

The answer is fairly obvious. It will be remembered that these phenomena occurred in us whenever the attention was re- 
moved from certain classes of sensations. Our problem was to get sufficient control of the attention to effect this removal of attention. In hysteria this removal of attention is effected by the anæsthesias of the subject. We would not, the histerique can not, attend to these sensations. Whatever else hysteria may be then, this, at least, seems most probable. It is a discase of the attention. An hysterical anæsthesia or paralysis is simply an inability to attend to sensations from this part. The second personality is simply the natural correlate of the anæsthesias, when these have become fixed. When they are variable, irregular subconscious acts form their correlate.

In closing it may be well to sum up a few of the more important generalizations from the work.

There are two kinds of attention, or two manifestations of it. One is physiological in its distribution, and determining what classes of sensations shall be brought into consciousness. Its failure means the dropping out of consciousness, for the time, of the particular group of sensations with regard to which it has failed. The other is distributed according to logical and associational elements. Its function is to establish associations among the different elements of consciousness, and to bring out the full meaning of sensations, etc. Its failure means loss of memory and failure of judgment, will, etc., but not loss of consciousness.

In all habitual acts, and acts involving nothing but simple memory, the function of the higher powers of the mind is inhibitive and controlling only, and not productive, for whenever, by failure of attention, the acts are removed from the influence of these controlling and inhibitory powers they go on just the same. Consciousness itself here appears to play a purely cognitive part.

The feeling of personality-that a given act is done by usalways disappears whenever our knowledge of the act is acquired purely by return sensations. Mere fore-knowledge alone is not enough to make the act seem personal; it must be the fore-knowledge or expectation represented by the group of feelings we have called, for convenience, the motor impulse. This motor impulse seems to introspection to be much more than a 
mere expectation in sensory terms. It seems to have a feeling background in it, entirely indescribable, in other terms, and perhaps representing a direct consciousness of a motor current from the higher centers to the lower.

The feeling of effort is not essential to self-consciousness. Its function seems to be to bring a center into a more responsive condition. It accompanies movements of voluntary attention apparently.

Hysteria is, at least, a disease of the attention. Its anæsthesias, etc., and their correlated subconscious acts represent the failure of the first kind of attention. The weakened memory and intellect, when it occurs, represents the failure of the second type. 